\title{
6
}

\section{Coordinated Primary Care}

Health systems nationally and globally are experiencing the need for higher performing, fully integrated primary care practices. Two main drivers of the need are the growing older population using more care and the shortage in the healthcare workforce including physicians. ${ }^{1}$ In 2014, the US had a shortage of 8073 primary care physicians. ${ }^{2}$ Some project that by 2025 , the US will need 14,900 to 52,000 more primary care physicians. ${ }^{3,4,5}$ Coordinated primary care is advantageous for everyone, but especially so for older patients with comorbidities and functional and cognitive limitations. Between 2000 and 2002, the average Medicare beneficiary saw two primary care physicians and five specialists annually. ${ }^{6}$ They also accessed other health services including diagnostics and pharmacy. Older adults are often unable to navigate a fragmented continuum of healthcare that includes multiple clinicians and medications. They need a single primary care office to provide coordination across specialties and care settings. Coordinated care optimizes health outcomes and has been shown to reduce health expenditures and unnecessary and redundant healthcare utilization.

This chapter overlaps with our chapter on palliative care because, as previously noted, palliative care and primary care for the older population 
with chronic conditions are one in the same. Other recurring themes in this chapter are value-based and person-centered care and the financial incentives for such care. Coordinated efficient primary care is inherently value-based and person-centered. The focus of this chapter is on health system organization and quality measures that support coordinated primary care. Patient-centered medical homes are leading the transformation to coordinated healthcare delivery in the US and abroad. Medical homes can enable primary care practices to achieve the triple aim of lower costs, better health outcomes (including patient satisfaction), and increased access to care. ${ }^{7}$

The medical home is a perfect fit for older adults who spend much more time interacting with the healthcare system. They want a medical home. (Erin Giovannetti, the National Committee for Quality Assurance)

\section{The Patient-Centered Medical Home}

\section{History}

In 1967, the American Academy of Pediatrics introduced the concept and term "medical home" as a description of a high-quality primary care provider that is accessible, family-centered, comprehensive, coordinated, compassionate, and culturally effective. Since, the International Conference on Primary Health Care, ${ }^{8}$ the World Health Organization, ${ }^{9}$ the Institute of Medicine, ${ }^{10}$ the American Academy of Family Physicians, ${ }^{11}$ the American College of Physicians, ${ }^{12}$ the Patient-Centered Primary Care Collaborative, ${ }^{13}$ and researcher Dr. Barbara Starfield have supported the medical home with impactful publications. In 2006 a group of large employers including IBM and leading primary care physician associations including the American Osteopathic Association, the American Academy of Family Physicians, the American College of Physicians, and the American Academy of Pediatrics formed the PatientCentered Primary Care Collaborative ${ }^{14}$ to promote the patient-centered medical home. Today the collaborative has 1000 multi-stakeholder members. 
Since its passage in 2010, the Patient Protection Affordable Care Act has many provisions that have contributed to the expansion of patientcentered medical homes. The medical home model exists around the world and continues to expand in the US. In their interview, Doctors Michael Barr and Erin Giovannetti describe the characteristics and outcomes of the patient-centered medical home. They also discuss the process of becoming recognized by the National Committee for Quality Assurance.

The patient-centered home model is better equipped to handle the complex care of patients with multiple chronic conditions who are more often older people. (Michael Barr, the National Committee for Quality Assurance)

\section{Dr. Erin R. Giovannetti and Dr. Michael S. Barr, National Committee for Quality Assurance}

Erin Giovannetti is a Senior Research Scientist and Michael Barr is the Executive Vice President of the Quality Measurement \& Research Group at the National Committee for Quality Assurance. ${ }^{15}$

The National Committee for Quality Assurance (NCQA) is committed to driving improvement in healthcare quality through research, development of evidence-based quality standards and performance measures, education and training, and advocacy. NCQA offers recognition, accreditation, and certification programs for a variety of care models and interventions. For the purpose of this book, we will examine the Patient-Centered Primary Care recognition program. To achieve recognition, primary care practices undergo a thorough multi-step review of 60 quality standards and report their annual quality and performance measures in over 40 areas. The NCQA formula for improvement is: measure, analyze, improve, repeat.

In our research, we define excellent quality care as care that enables people to reach their goals even if their hemoglobin A-1C is not precisely where their clinicians wanted to be. This requires a shift from care directed by the provider's goals to care directed by the patient's goals. (Erin Giovannetti) 


\section{Characteristics}

Patient-centered medical homes (PCMHs) are also referred to as primary care medical homes and simply, medical homes. A medical home functions as a single point of care coordination and management for their patients. The care team consists of doctors, nurses, health educators, pharmacists, and other clinicians. The patient is included in all care decisions and the care plan is individualized to the health profile and care preferences of the patient. In her interview, Erin described research that the NCQA is conducting into ways that health providers can better align care with the individual preferences of their patients. Medical homes also educate and encourage their patients to practice disease self-management and engage in prevention.

Patient-centered medical homes maintain the goal of improving safety and reducing the use of unnecessary, redundant, and low-value care. Medical homes use technology to improve efficiencies. The patient records are updated in real time and are accessible at all hours. Many practices use telehealth to connect to patients after hours.

The value-based reimbursement models in the US provide much incentive for providers to keep their patients out of the emergency departments (EDs) and hospitals. Access to care is a critical feature of the medical home. Patient-centered medical homes organize their scheduling in a way that enables them to provide same-day routine medical and urgent care. When patients do not have access to their primary care office, they are forced to go to the ED. Many of their health concerns are nonurgent. It is estimated that 30 to 50 percent of the ED visits in the US are for nonurgent needs. ${ }^{16,17,18}$ This unnecessary care costs the US health system millions of dollars annually. We will delve more deeply into emergency care in our subsequent chapter, Emergency Medicine in the Home and Community.

\section{Outcomes}

Staff burnout ${ }^{19}$ and turnover are detrimental to healthcare practices both organizationally and financially. Michael Barr noted that physician and medical staff burnout decreases in practices that have become 
patient-centered medical homes. Group Health Cooperative in Seattle, Washington, realized a 20 percent decline in staff burnout one year after implementation of the medical home model. ${ }^{20}$ The same practice saw higher patient satisfaction, quality, cost savings, and lower rates of provider burnout two years after their transformation to a medical home. ${ }^{21}$ The Veterans Administration Health System also experienced lower burnout rates among their primary care employees after adopting the medical home model. ${ }^{22}$ There is a plethora of evidence-based research on the National Committee for Quality Assurance website. ${ }^{23}$ The research presents conclusive evidence that, when implemented correctly, recognized patient-centered medical homes improve access, quality (including patient satisfaction), and lower healthcare utilization and costs.

Our recognition program represents the best thinking from a variety of stakeholders around the country, expert consensus, public opinion, and eight years of experience of the National Committee for Quality Assurance. (Michael Barr)

\section{Recognition ${ }^{24}$}

Michael Barr explained that to receive recognition, a practice must meet a specified number of standards that include:

- Patient-centered access;

- Team-based care;

- Population health management, care management, and support;

- Care coordination and care transitions;

- Performance management and quality improvement.

Within those standards there are six elements that represent the core of the medical home model. Practices must have all six of these elements to become recognized:

- Patient-centered appointment access;

- The Practice Team ${ }^{25}$;

- Use of data for population management purposes; 
- Care planning and self-care support;

- Referral tracking and follow-up;

- Continual quality improvement.

Accreditation or recognition from NCQA gives practices the opportunity to demonstrate their commitment to quality, access, and patient satisfaction. To date, the NCQA has recognized over 11,000 patient-centered medical home primary care centers, representing 40 to 60 million patients. Some Veterans Health Administration facilities are also recognized patient-centered medical homes.

When a veteran sees his primary care physician and complains of an ongoing hip problem, that physician can establish an immediate consult with an orthopedic doctor or a rehabilitation therapist, in the same building. If those doctors need X-rays, lab tests, or diagnostic studies, they are done in house, usually the same day. If those studies indicate the need for surgery, a consult can be established immediately, with appropriate surgical clearance, and an operation conducted, all in the same facility, without a need to travel from one physician or facility to another. (Dr. Erik Langhoff)

\section{Dr. Erik Langhoff, James J. Peters VA Medical Center}

Dr. Erik Langhoff is the Director of the James J. Peters VA Medical Center. $^{26}$

The Veterans Health Administration is especially positioned to impact the healthcare of older adults because their patient population is older and has higher rates of comorbidity. Additionally, 25 to 30 percent have physi$\mathrm{cal}$ and/or other health issues that are related to their time in the military.

The Veterans Health Administration (VHA) operates one of the largest healthcare systems in the world consisting of 152 hospitals, 800 community clinics, 126 nursing homes, and 35 domiciliaries. VHA hospitals and research facilities have provided at least some training for 60 percent of all medical residents in the US. The VHA is strongly committed to research and has supported prominent researches in developing 
groundbreaking health innovations such as the exoskeleton. ${ }^{27} \mathrm{~A}$ comparison of hospital-level quality and patient experience data of non-VHA hospitals to VHA hospitals showed that the VHA outperformed on six of the nine patient safety indicators. The VHA hospitals also exhibited better readmission and mortality rates. ${ }^{28}$

Any discovery made in the Department of Veterans Affairs is ultimately shared with the entire world and benefits all of humanity.

Headquartered in Bronx, New York, the James J. Peters VA Medical Center serves an enrolled population of approximately 50,000, and an active user population of approximately 25,000 veterans. The James J. Peters VA Medical Center serves approximately 1700 patients per day. The Center has over 200 impatient hospital beds and 68 nursing home beds and supports community outpatient clinics in Queens, Yonkers, and White Plains, New York.

Here we can provide value over volume because, while we are tasked with being responsible stewards of the public money, our salary is not dependent on billing and we do not chase profit.

\section{Efficiency and Value-Based Care}

Erik is originally from Denmark and is familiar with a well-functioning, government-run healthcare system. Erik launches and oversees continual multiple Lean Six Sigma projects in his commitment to streamlined efficiency. In his interview Erik explained that billing does not drive the Veterans Health Administration because they are reimbursed by capitated payments. As mentioned in Chap. 1, with capitated payment arrangements, providers are paid a set amount per patient. This creates an inherent incentive to maintain an efficient system of care coordination that supports keeping their patient population healthy and out of the emergency department and hospital. 


\section{Access}

Maintaining access to care is a vital component of the James. J. Peters VA Medical Center. Increased access provides veterans with an alternative to going to the emergency department. A unique aspect of the VHA is the ability for physicians to work across state borders in person or via telemedicine. Physicians outside of the VHA must be licensed in the state where they practice. Erik and his colleagues are able to practice at all of the VHA facilities around the country. This is especially important because, at any moment, a specialist can be brought onto the care team remotely. The electronic health records of the veterans are also available at all VHA care facilities. If a veteran wishes to see a specialist in another state, they may, and their records will be available and up to date. Many VHA facilities also have evening and weekend walk-in clinics. By the end of the year, Erik plans to have the James J. Peters VA Medical Center offer same-day access to primary care and mental health services. The James J. Peters VA Medical Center is in the process of offering telemedicine from emergency department so veterans can call and speak with an emergency department physician from home. The James J. Peters VA Medical Center also manages a telephone triage center that is available to approximately 900,000 veterans. The service will soon be available day and night. The Center provides home-based primary care and hospital-level care in a home for their older adults. Technology is an important aspect of the VHA care coordination.

\section{Technology}

In 1990 the Veterans Health Administration designed and built one of the most comprehensive electronic health records (EHR) in the world. At the time it was implemented, it was fully networked across the country in all VHA facilities. It was designed around patient care and coordination. More recently, the VHA upgraded their EHR to the same system that is used by the Department of Defense, thus capturing the Veteran's health record from the time of service through the end of their lives. James J. Peters VA Medical Center was one of the first to provide telenephrology ${ }^{29}$ and telekidney disease monitoring. 
The department of Veterans Affairs uses electronic prescription technology. Clinicians enter the prescription into the computer and the medication is dispersed via mail by a centralized pharmacy. The patient also has the option of picking up their prescription in person. They use the same process for tests. The order for a test such as an $\mathrm{x}$-ray is entered into the EHR. When the test is complete, it is automatically filed into the EHR. The complete real-time patient health record is available in one place at all times and in all locations. Demographic data is also included in the electronic health record and informs the care team about the social determinants that drive much of the health outcomes of their patients. Patients also have access to their EHR, including lab results, prescriptions, diagnoses, and contact information for their primary care doctor.

\section{Barriers to Coordinated Primary Care}

Changing an existing system of care delivery presents challenges that can be a strong barrier. It requires a full commitment by management and employees. Technology can act as a barrier when offices do not have electronic health systems or when those systems are not interoperable. Reimbursement policy can also act as a barrier to coordinated care. Reimbursements that are not value-based can dissuade providers from making the changes that are necessary to build an efficient, coordinated primary care practice.

It is our hope that patient-centered medical homes and other efficient coordinated primary care practices continue to spread nationally and globally to meet the needs of the older population and reduce healthcare costs.

As a continuation in our efforts to seek out cost-effective and personcentric models of care that reach into the home and community, we found four programs that have yielded impressive results in cost, quality, and health outcomes-including patient satisfaction. In the following chapter, we write about the importance of delivering acute and hospitallevel care in the home of older adults and describe the DispatchHealth, Northwell Health, Call9, and Hospital at Home care models.

The full interviews can be found at this link: www.accessh.org/agingwell. 


\section{Notes}

1. WHO (2014). A universal truth: No health without a workforce. http:// www.who.int/workforcealliance/knowledge/resources/GHWA-a_universal_truth_report.pdf?ua=1. Accessed April 2017.

2. Fodeman, J. \& Factor, P. (2015). Solutions to the primary care physician shortage. American Journal of Medicine, 128(8), 800-801.

3. Dall, T., West, T. Chakrabarti, R., \& Lacobucci, W. (2014). The complexities of physician supply and demand 2016 Update: Projections from 2014 to 2025. IHS. https://www.aamc.org/download/426248/ data/thecomplexitiesofphysiciansupplyanddemandprojectionsfrom 2013to2.pdf. Accessed April 2017.

4. Peterson, S.M., Liaw W.R., Phillips, R.L., Rabin, D.L., Meyers, D.S., \& Bazemore A.W. Projecting US primary care physician workforce needs: 2010-2025. Annals of Family Medicine, 10(6), 603-509.

5. Health Resource Administration (2013). Projecting the supply and demand for primary care practitioners through 2030. https://bhw.hrsa. gov/health-workforce-analysis/primary-care-2020. Accessed April 2017.

6. Bodenheimer, T. (2008). Coordinating Care-A perilous journey through the health care system. The New England Journal of Medicine, 358 (10), 1064-71.

7. Taylor, E.F., Genevro, J., Peikes, D., Geonnotti, Wang, W., \& Meyers, D. Building quality improvement capacity in primary care. Agency for Healthcare Research and Quality. https:/www.ahrq.gov/professionals/ prevention-chronic-care/improve/capacity-building/pcmhqi2.html. Accessed April 2017.

8. (1978). Declaration of Alma-Ata. International Conference on Primary Health Care, Alma-Ata, USSR, 6-2. http://www.who.int/publications/ almaata_declaration_en.pdf. Referenced April, 2017.

9. World Health Organization (1978). Primary Health Care. Report of the international conference on primary healthcare. http://apps.who.int/ iris/bitstream/10665/39228/1/9241800011.pdf. Accessed April 2017.

10. Donaldson, M.S., Yordy, K.D., Lohr, K.N., \& Vanselow, N.A. (1996). Primary care. American health in a new era. Institute of Medicine, National Academy Press. https://www.nap.edu/read/5152/chapter/1. Accessed April 2017.

11. Kahn, N.B. (2004). The future of family medicine: A collaborative project of the family medicine community. Annals of Family Medicine. 
2(suppl), S3-32. http://www.annfammed.org/content/2/suppl_1/S3. full. Accessed April 2017.

12. Barr, M., Harris, J., Bronson, D.L., Ake, J., Barry, P.P., Cooke, M, Diamond, H.S., Levine, J.S., Mayer, M.E., McGinn, T., McLean, R.M., Starkweather, A.E., \& Turtin, E. (2006). The advanced medical home: A patient-centered, physician-guided model of health care. American College of Physicians. https://www.acponline.org/acp_policy/policies/ adv_medicalhome_patient_centered_model_healthcare_2006.pdf. Accessed April 2017.

13. Nielsen, M., Langner, B., Zema, C., Hacker, T., \& Grundy Paul (2012). Benefits of implementing the primary care patient-centered medical home: A review of cost \& quality results. Patient-Centered Primary Care Collaborative. https://www.pcpcc.org/sites/default/files/media/benefits_ of_implementing_the_primary_care_pcmh.pdf. Accessed April 2017.

14. https://www.pcpcc.org. Accessed April 2017.

15. http://www.ncqa.org/HomePage.aspx. Accessed April 2017.

16. Carret, M., Fassa, A., \& Domingues, M. (2009). Inappropriate use of emergency services: A systematic review of prevalence and associated factors. Cadernos Saúde Pública, 25(1), 7-28.

17. Durand, A., Gentile, S., Devictor, B., Palazzolo, S., Vignally, P, Gerbeaux, P, \& Sambuc, R. (2010). ED patients: How nonurgent are they Systematic review of the emergency medicine literature. American Journal of Emergency Medicine, 29(3), 333-45.

18. Xin, H., Kilgore, M.L., Sen, B., \& Blackburn, J. (2015). Can nonurgent emergency department care costs be reduced? Empirical evidence from a U.S. nationally representative sample. Journal of Emergency Medicine, 49(3), 347-354.

19. High levels of emotional exhaustion and low sense of personal accomplishment.

20. Reid, R.J., Fishman, P.A., Yu, O., Ross, T.R., Tufano, J.T., Moman, J.P., \& Larson, E.B. (2009). Patient-centered medical home demonstration: A prospective, quasi-experimental, before and after evaluation. American Journal of Managed Care, 15(9), 371-e87.

21. Reid, R.J., Coleman, K., Johnson, E.A., Fishman, P.A., Hsu, C., Soman, M.P., Trescott, C.E., Erikson, M. \& Larson, E.B. (2011). The group health medical home at year two: Cost savings, higher patient satisfaction, and less burnout for providers. Health Affairs, 29(5), $835-843$. 
22. Helfrich, C.D., Dolan, E.D., Simonetti, J., Reid, R.J., Joos, S., Wakefield, B.J., Schectman, G., Stark, R., Fihn, S.D., Harveys, H.B., \& Nelson, K. (2014). Elements of team-based care in a patient-centered medical home are associated with lower burnout among VA Primary care employees. Journal of General Internal Medicine, 29 (Suppl 2), 659-686.

23. http://www.ncqa.org/programs/recognition/practices/pcmh-evidence. Accessed April 2017.

24. http://blog.ncqa.org/ncqa-launches-pcmh-redesign/. Accessed May 2016.

25. Team-based organizational requirements.

26. https://www.bronx.va.gov/. Accessed April 2017.

27. https://www.va.gov/HEALTH/NewsFeatures/2017/March/RoboticBrace-for-Veterans-of-Spinal-Cord-Injury.asp. Accessed April 2017.

28. Blay, E., DeLancey, J.O., Hewitt, D.B., Chung, W., Bilimoria, K. (2017). Initial public reporting of quality at Veterans Affairs vs nonveterans affairs hospitals. JAMA Internal Med. https://doi.org/10.1001/ jamainternmed.2017.0605.

29. A nephrologist specializes in kidney care.

Open Access This chapter is licensed under the terms of the Creative Commons Attribution 4.0 International License (http://creativecommons.org/licenses/ by/4.0/), which permits use, sharing, adaptation, distribution and reproduction in any medium or format, as long as you give appropriate credit to the original author(s) and the source, provide a link to the Creative Commons licence and indicate if changes were made.

The images or other third party material in this chapter are included in the chapter's Creative Commons licence, unless indicated otherwise in a credit line to the material. If material is not included in the chapter's Creative Commons licence and your intended use is not permitted by statutory regulation or exceeds the permitted use, you will need to obtain permission directly from the copyright holder.

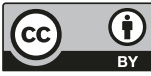

